\title{
Factors influencing nursing care in a surgical intensive care unit
}

\author{
J. P. Raj, Nagamani Sen, K. R. John*
}

\begin{abstract}
Context: The total time spent in nursing care depends on the type of patient and the patient's condition. We analysed factors that influenced the time spent in nursing a patient. Aims: To analyse the factors in a patient's condition that influenced time spent in nursing a patient. Materials and Methods: This study was performed in the Surgical Intensive Care Unit of a tertiary referral centre, over a period of one month. The total time spent on a patient in nursing care for the first 24 hours of admission, was recorded. This time was divided into time for routine nursing care, time for interventions, time for monitoring and time for administering medications. Statistical analysis used: A backward stepwise linear regression analysis using the age, sex, diagnosis, type of admission and ventilatory status as variables, was done. Results: Patients admitted after elective surgery required less time (852.4 \pm 234.1 minutes), than those admitted after either emergency surgery (1069.5 \pm 187.3 minutes), or directly from the ward or the emergency room (1253.7 \pm 42.1 minutes). Patients who were ventilated required more time (1111.5 \pm 132.5 minutes), than those brought on a T-piece (732.2 \pm 134.8 minutes or extubated (639.5 \pm 155.6 minutes). The regression analysis showed that only the type of admission and the ventilatory status significantly affected the time. Conclusions: This study showed that the type of admission and ventilatory status significantly influenced the time spent in nursing care. This will help optimal utilization of nursing resources.
\end{abstract}

Key words: Time, nursing nare, ICU, nursing time, allocating time.

In an intensive care unit, the health care professional who spends maximum time with the patient, is the ICU nurse. To ensure that the patient's needs are adequately taken care of, a nurse to patient ratio of one is to one, is needed. There are occasions when this ratio may not be adequate. ${ }^{[1-3]}$

We are in an age where critical care medicine is costly ${ }^{4-}$ ${ }^{7]}$ and where specialised nursing personnel are scarce. ${ }^{[1]}$

\section{From:}

Departments of Surgical Intensive Care Unit and ${ }^{*}$ Community Health,

Christian Medical College, Vellore, India

\section{Correspondence:}

John Prakash Raj, Surgical Intensive Care Unit, Christian Medical College, Ida Scudder Road, Vellore - 632 004, India.

E-mail: johnprakash.raj@cmcvellore.ac.in
In such a situation, providing adequate care to a patient is difficult. Often the nurse to patient ratio becomes less than ideal, compromising on the quality of care. ${ }^{[2,3]}$ With such a background, it is important to optimise the time a nurse spends with a patient. This would lead to utilisation of a minimum number of nurses, without compromising on the quality of care delivered.

Studies on the time spent by nurses on patients have been done in the past. ${ }^{[8-13]}$ Several scoring systems like the Therapeutic Intervention Scoring System (TISS), ${ }^{[14]}$ the Time Oriented Scoring System (TOSS) ${ }^{[15]}$ and the Nursing Care Recording System (NCS) ${ }^{[1]}$ have been devised, both to measure and to predict the amount of time, a nurse needs to give in the care of each patient.

Free full text available from www.ijccm.org 
These scoring systems help to estimate the amount of time required for nursing care.

While studies have been done on the time a nurse spends in the ICU, ${ }^{[8,9,15]}$ few studies have been done to determine factors that may influence this time. Such factors may include the need for mechanical ventilation, number of medications to be administered and procedures performed. In addition, the time spent by the nurse may also be influenced by the age of the patient, the disease and interventions that may be required. Severity scores like the APACHE II score, ${ }^{[16]}$ the SAPS score, ${ }^{[17]}$ indicate the severity of illness. However, they give very little indication of the factors that may influence the time involved in nursing a patient with a particular score. Knowledge of this type would be useful, to help in planning nursing care of patients in an ICU.

This study was done in a ten-bedded Surgical ICU of a tertiary care centre. The surgical ICU receives about 900 admissions every year. The average length of stay of patients is about 2.3 days. A total of 21 nurses including the head nurse, staff the unit. This works to a nursepatient ratio of $1: 2$, at the best of times. Improving this ratio would mean an increased cost, both to the patient (who funds his treatment) and to the hospital. It was therefore important to use the time available for nursing care efficiently, to ensure adequate patient care.

The study was done with the objective of measuring the total amount of time that a nurse spends on each patient and the various components of that time. We also analysed the various factors that played a role in the utilisation of this available time. Knowledge of these factors would help in more optimal utilization of nursing resources.

\section{Materials and Methods}

Fifty consecutive patients who were admitted into the Surgical Intensive Care Unit during a one month period, were included in the study. This study was done with the permission of the institution's Research Committee. As the study did not involve patients, informed consent was not required. Consent of the nurses studied, was not taken to avoid bias.

Before starting this study, every nursing procedure was timed and an average of ten such timings was taken.
Since all nurses follow standard protocols for each procedure in the ICU, there was very little change in the time for each procedure, between nurses.

At admission, the patient's name, age and sex were recorded. Patients were categorised into three types of admission: following elective surgery; following emergency surgery and direct admissions from the ward or the Emergency Room (ER). The need for mechanical ventilation was noted. Admissions with an endotracheal or tracheostomy tube in situ, were also recorded. Interventions carried out were also recorded.

The total time a nurse spent on a patient for the first twenty-four hours of stay in the ICU, starting from the moment the patient was transferred to the ICU, was recorded. The first twenty-four hours was taken, because we felt that the most interventions are carried soon after admission and the nursing input is maximum during that period.

The time that a nurse spent for the first 24 hours after admission, was calculated by listing the procedures done during that period and using the average time that had been calculated earlier. This time was recorded under four categories: the time taken for routine nursing care; the time taken for monitoring; the time taken for administering medications and the time taken for interventions. Where an intervention like a central venous line, tracheostomy or endotracheal intubation was done, the actual time spent by the nurses was recorded. In addition, the time taken in admitting or discharging (if a patient was discharged within 24 hours), was recorded. If a patient died within twenty-four hours of admission, the time taken for death care was recorded. During this period, the actual time taken for various procedures was timed at random intervals, to ensure that there was no variation from the average calculated earlier. The time spent by nurses on breaks or administrative work not connected with patient care, was not included in the time taken for patient care.

The TISS score for each patient during the first twentyfour hours was calculated for each patient.

\section{Statistical analysis}

The results were analysed by using age, sex, the diagnosis, the type of admission and the need for 
ventilation as variables. These were compared with the total time taken, the time taken for routine nursing care, the time taken for monitoring, the time taken for administering medication, the time taken for interventions and the TISS score. Analysis of variance (ANOVA) tests were done to determine significance. A probability of < 0.05 was considered significant. A backward step wise linear regression analysis using these variables was done, to determine the influence each of these variables had on the total time. All values are expressed in minutes, \pm standard deviation.

\section{Results}

\section{Total time}

The average time spent by a nurse on each patient during the first twenty-four hours of their stay, was 967.7 \pm 244.1 minutes. The average TISS score for the first twenty-four hours, was $20.72 \pm 6.47$.

\section{Age}

Patients between the ages of 31 and 50 required maximum time for nursing care. Table 1 gives details of the time required by various age groups. Patients who were more than 50 years required less time for nursing care, regardless of the type of admission.

\section{Sex}

There was no statistical difference in the total time required for nursing care between the sexes. Males required an average time of $983.9 \pm 247.7$ minutes, while females required an average time of $929.7 \pm 231$ minutes.

\section{Primary diagnosis}

Patients admitted with hollow viscus perforations, trauma and eclampsia, required significantly more time in nursing. The average time spent in nursing care of these patients was 1080.6 minutes, compared to an average time of 888 minutes for the other categories.

\section{The type of admission}

Table 1: The total time spent on nursing care according to age. $(P=0.05)$

\begin{tabular}{lccc}
\hline Age (years) & Number & Time (minutes) & TISS score \\
$<20$ & 7 & $958.9 \pm 175.1$ & $22.4 \pm 4.6$ \\
$21-30$ & 11 & $853.2 \pm 191.6$ & $18.4 \pm 6$ \\
$31-40$ & 9 & $1124.2 \pm 184.5$ & $22.7 \pm 4.6$ \\
$41-50$ & 7 & $1155.4 \pm 162.6$ & $25.1 \pm 5.6$ \\
$51-60$ & 8 & $951.3 \pm 315.3$ & $20.1 \pm 8.3$ \\
$>60$ & 8 & $808.9 \pm 179.5$ & $17 \pm 5.2$ \\
\hline
\end{tabular}

Patients who were admitted directly from either the ward, or the ER used significantly $(P=0.00006)$ greater amounts of nursing time, compared to patients who were admitted under the other categories. Patients following elective surgery required $852.4 \pm 234.1$ minutes of nursing time. This was significantly lower, compared to admissions following emergency surgery $(n=21 ; 1069.5$ \pm 187 minutes), or direct admissions form either the ward, or the $\operatorname{ER}(n=3 ; 1253.7 \pm 42.1)$. The TISS score statistically correlated with the time for all three categories.

\section{Time spent on ventilated patients}

Patients who required mechanical ventilation required significantly more nursing time than patients not ventilated. Among patients who did not require ventilation, patients brought with an endotracheal tube in situ, required more time than patients who were brought extubated. This difference was not statistically significant. The results are summarised in Table 2.

\section{Time for routine nursing care}

Activities recorded under routine nursing care included bath, back care, positioning, toileting, change of dressing, feeding and similar nursing activities. The age, sex, primary diagnosis and type of admission, did not significantly influence time required for routine nursing care. Ventilated patients required significantly more time for routine nursing care, than other categories of patients [Table 3]. Patients who were admitted after emergency surgery or directly from the wards, or emergency room, also required more time for routine nursing care.

Table 2: Time taken for nursing care according to the need for ventilation. $(P<0.0001)$

\begin{tabular}{lccc}
\hline & Number & Time & TISS \\
Extubated & 8 & $639.5 \pm 155.6$ & $12.6 \pm 2.7$ \\
On a T-piece & 9 & $732.2 \pm 134.8$ & $15.2 \pm 2.4$ \\
Ventilated & 33 & $1111.5 \pm 132.5$ & $24.2 \pm 4.9$ \\
\hline
\end{tabular}

Table 3: The time taken for routine nursing care activities $(P<0.0001)$.

Only monitoring

Patient on a T-Piece

Ventilated patients

All patients

Emergency admissions

Elective admissions

$\begin{array}{cc}\text { Number } & \text { Time } \\ 8 & 204 \pm 79.6 \\ 9 & 247.8 \pm 56.5 \\ 33 & 450.6 \pm 57.9 \\ 50 & 374.6 \pm 123.1 \\ 24 & 407 \pm 110 \\ 26 & 344.7 \pm 127\end{array}$




\section{Time taken for monitoring}

Monitoring included recording of various haemodynamic and respiratory parameters, intake and output charts and neurological monitoring where necessary. The time taken for monitoring patients ranged from 140 to 300 minutes in the twenty-four hour period studies, with an average of $262.8 \pm 41.6$ minutes. The age, sex, primary diagnosis and type of admission, did not significantly influence the time taken for monitoring. Patients who required mechanical ventilation required significantly more time $(279.4 \pm 23.4$ minutes $)$ for monitoring, than non ventilated patients $(230.7 \pm 49.5$ minutes; $P=<0.0001$ ).

\section{Time taken for interventions}

Interventions included setting up intravascular lines, endotracheal intubation, tracheostomy and tube thoracostomy. The time taken for interventions was significantly more in patients who were admitted either directly from the wards or after emergency surgery, compared to patients admitted after elective surgery (130.6 \pm 98 versus $54 \pm 50$ minutes; $P=0.001$ ). Patients with hollow viscus perforations and patients with trauma, also required more time for interventions (138.1 \pm 98 minutes and $147.5 \pm 85.2$ minutes respectively).

\section{Time taken for administering medications}

The average time taken for administering medications was $165.6 \pm 52.2$ minutes. Patients admitted after emergency surgery and direct admissions from the wards, required significantly more time for medications $(204.1 \pm 33.2$ minutes and $228 \pm 10$ minutes respectively), than patients who underwent elective surgery (127.2 \pm 34.6 minutes; $P=<0.0001)$. Patients with bowel perforations, trauma and sepsis, required significantly $(P<0.0001)$ more time $(216.2 \pm 12.2$ minutes) for administering drugs, than other categories of patients (139.5 \pm 44.3 minutes).

\section{Multiple regression}

Using the variables age, sex, the disease condition, type of admission and ventilatory status, a backward stepwise linear regression was done. Only the type of admission and the ventilatory status significantly influenced total time required for nursing. The $R^{2}$ value for this was 0.622 [Table 4]. The $\mathrm{R}^{2}$ value using these variables and the TISS score was 0.527 .
Table 4: Results of the backward stepwise linear regression analysis

\begin{tabular}{lccccc}
\hline Variable & B & $\begin{array}{c}\text { Standard } \\
\text { error }\end{array}$ & Beta & T & $\begin{array}{c}\text { Significance } \\
\text { of T }\end{array}$ \\
Ventilatory status & -163.97 & 29.9 & -0.620 & -6.604 & 0.0000 \\
Type of admission & 135.13 & 37.8 & 0.3360 & 3.577 & 0.0008 \\
Constant & 1054.42 & 86.0 & & 12.25 & 0.0000 \\
\hline
\end{tabular}

$F=38.63 ; R^{2}=0.622 ;$ Significance of $F=0.0000$

\section{Discussion}

The above results show that the type of admission and the need for ventilation, appears to be the main factors influencing the time a nurse requires for the care of a patient.

While the sex of the patient did not appear to influence the total time, younger patients required more time for nursing care, regardless of their underlying condition. This agrees with another study done in an ICU, where patients who were more than 75 years of age had a lower TISS score, than younger patients. This was seen even when factors like severity, need for mechanical ventilation, mortality rate and the disease process were taken into account. ${ }^{[18]}$

Patients who were admitted after emergency surgery, or directly from the wards, required significantly more time than patients admitted after routine, elective surgery. Looking at the break up of time consumed in various nursing activities [Figure 1], there was no difference between the two groups in the time taken for routine nursing care $(409.1 \pm 107.3$ versus $349.7 \pm 127.7$ minutes; $P=0.21)$ and monitoring $(270.4 \pm 21.2$ versus $257.3 \pm 47.9$ minutes; $P=0.5$ ). However, these patients required significantly more time for interventions and

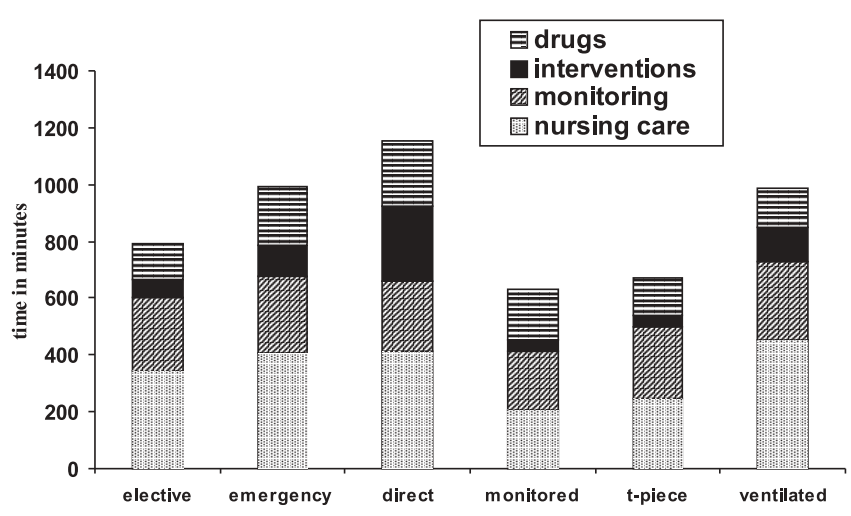

Figure 1: Bar chart showing various components of time required for nursing care in patients plotted against type of admission and the need for ventilation. 
medications. The TISS score in these patients were also significantly higher. Interventions such as inserting intravascular lines and intubations (for direct admissions), accounted for most of the time taken in these patients. These patients were more likely to be on ionotropic supports, multiple antibiotics and were more likely to require transfusion of blood and blood products. These contributed to the increased time required for medications.

Patients who were ventilated, required significantly more time than patients who were either brought extubated, or brought with an endotracheal tube or tracheostomy in situ. These patients required more time for routine nursing care $(450.5 \pm 58.8$ versus $227.2 \pm$ 71.7 minutes; $P=0.0000)$. These patients also required more time for interventions and medications. Ventilated patients were more likely to be sedated than non ventilated patients. This necessitates more frequent back care and attention, consuming more time. Moreover, there were more patients who were ventilated following an emergency surgery, than after an elective surgery. Seventy-nine percent of the patients who were admitted after an emergency surgery required ventilation, whereas $53 \%$ of the patients after an elective surgery, required ventilation.

A patient who has undergone elective surgery and is brought for extubated to the ICU for monitoring only will require about 558 minutes ( 9 hours, 18 minutes). While such patients ideally require a high dependency unit and not intensive care, they may be admitted to the ICU in the absence of a dedicated high dependency unit. For these patients, a nurse to patient ratio of 1:2 or even $1: 3$, may be adequate. On the other hand, a patient who comes directly from the ward and requires ventilation, will need about 1258 minutes (20 hours, 58 minutes) of nursing care per day. Here, a 1:1 ratio is mandatory and occasionally extra help may be required to ensure adequate care of this patient.

We believe that this study will be useful in the planning of nursing care in the ward. The time required for various types of patients can be easily calculated just by knowing the type of admission and the ventilatory status of the patient. The allocation of patients to a particular nurse can be done, depending on the time required. This would help in optimising both, the care offered as well as the number of nurses needed to staff the ICU.

\section{References}

1. Hudson-Civetta JA. Allocating Nursing Care. In: Civetta JM, Taylor RW, Kirby RR Editors. Critical Care. JB Lippincott: Philadelphia; 1992.

2. Merkouris A, Papathanassoglou ED, Pistolas D, Papagiannaki V, Floros J, Lemonidou C. Staffing and organisation of nursing care in cardiac intensive care units in Greece. Eur J Cardiovasc Nurs 2003:2:123-9.

3. Amaravadi RK, Dimick JB, Pronovost PJ, Lipsett PA. ICU nurseto-patient ratio is associated with complications and resource use after esophagectomy. Intensive Care Med 2000;26:1857-62.

4. Birnbaum M, Walleck CA. Rationing Health Care: Impact on Critical Care. Crit Care Clin 1993;9:585-602.

5. Kirton OC, Civetta JM, Hudson-Civetta JA. Cost Effectiveness in the Intensive Care Unit. Surg Clin North Am 1996;76:175-200.

6. Welton JM, Meyer AA, Mandelkehr L, Fakhry SM, Jarr S. Outcomes of and resource consumption by high-cost patients in the intensive care unit. Am J Crit Care 2002;11:467-73.

7. Carson SS, Bach PB. The epidemiology and costs of chronic critical illness. Crit Care Clin 2002;18:461-76.

8. Hudson J, Caruthers T, Lantiegne K. Intensive care nursing requirements: Resource allocation according to patient status. Crit Care Med 1979;7:69-75.

9. Plati C, Lemonidou C, Priami M, Baltopoulos G, Mantas J. The Intensive care units in greater Athens:needs and Resources. Intens Crit Care Nurs 1996;12:340-5.

10. Cullen DJ, Civetta JM, Briggs BA, Ferrara LC. Therapeutic Intervention Scoring System: A method for quantitative comparison of patient care. Crit Care Med 1974;2:57-60.

11. Hjortso E, Buch T, Ryding J, Lundstrom K, Bartram P, Dragsted $\mathrm{L}$, et al. The nursing care recording system:A preliminary study of a system for assessment of nursing care demands in the ICU. Acta Anaesthesiol Scand 1992;36:610-4.

12. Vitacca M, Clini E, Porta R, Ambrosino N. Preliminary results on nursing workload in a dedicated weaning centre. Intens Care Med 2000;26:796-9.

13. Adomat $\mathrm{R}$, Hicks $\mathrm{C}$. Measuring nursing workload in intensive care: an observational study using closed circuit video cameras. J Adv Nurs 2003;42:402-12.

14. Miranda DR, Rijk A, Schaufeli W. Simplified Therapeutic Intervention Scoring System: The TISS -28 items-Results from a multicenter study. Crit Care Med 1996;24:65-73.

15. Italian Multicenter Group of ICU research (GIRTI). Time oriented score system (TOSS): a method for direct and quantitative 
assessment of nursing workload for ICU patients. Intens Care Med 1991;17:340-5.

16. Knaus WA, Draper EA, Wagner DP, Zimmerman JE. APACHE II: A severity of disease classification system. Crit Care Med 1985;13:818-29.

17. Le Gall JR, Loirat P, Alperovitch A, Glaser P, Granthil C, Mathieu
D, et al. A simplified acute physiologic score for ICU patients. Crit Care Med 1984;12:975-7.

18. Castillo-Lorente E, Rivera-Fernandez R, Varquez-Mata G. Limitation of therapeutic activity in elderly critically ill patients. Project for the Epidemiological Analysis of Critical Care Patients. Crit Care Med 1997;25:1643-8. 